\title{
Thermal fluctuation constants of PVC elements of different cross-sections
}

\author{
Vladislav Danilov ${ }^{*}$ and Alexander Erofeev \\ Institute of Architecture, Civil Engineering and Transport, Tambov State Technical University, 112, \\ 'E', Michurinskaya st., Tambov 392000, Russia
}

\begin{abstract}
Consideration of the durability of building materials from a thermal fluctuation position is the most difficult, but at the same time the most adequate method now. Since this concept is insensitive to changes in the physical structure, it becomes necessary to consider not only the material, but also the configuration of the structure. This will make it possible to bring the simplified theoretical ideas about the performance of a building material in a structure closer to real conditions. Thus, the aim of the work is to compare the destruction mechanism of PVC sheet elements of solid section and composite section from the thermal fluctuation position. To achieve this goal, the initial data for finding thermal fluctuation constants (durability of PVC plates at non-critical stress) were determined by an experimental method. Based on the initial data, the thermal fluctuation constants for each section were determined by the graphic-analytical method. During the comparative analysis, it is proposed to introduce a coefficient into the Zhurkov's equation, which will consider the configuration of the section. It was also determined that for PVC sheet elements of composite cross-section in two layers, this coefficient is $k_{c}=$ 2. Considering the configuration of the cross-section when determining the thermal fluctuation dependences will increase the quality of predicting the durability of the building material.
\end{abstract}

\section{Introduction}

Now the issues of durability and predicting performance are considered from the empirical method of limit states. Moreover, it is established that for the strength and deformability of most materials, the temperature-time dependence is clearly traced [1-4].

This dependence is characterized by the destruction of a solid body not only from mechanical loads, but also due to the kinetic energy of the particles arising from the thermal motion of the atoms. In other words, the destruction is considered as a thermal activation process in time. Such destruction is not critical, but develops over time $[1,5,6]$. The stated principle is the basic concepts of the thermal fluctuation concept on which this work is based.

The thermal fluctuation concept is expressed mathematically as follows [7-9]:

* Corresponding author: vm.danilov@outlook.com 


$$
\tau=\tau_{m} \cdot \exp \left[\frac{U_{0}-\gamma \cdot \sigma}{R} \cdot\left(\mathrm{T}^{-1}-\mathrm{T}_{m}^{-1}\right)\right]
$$

where, $\tau$ - the durability of the material or the time until reaching one of the limiting conditions, $\mathrm{c} ; \mathrm{R}$ - universal gas constant, $\mathrm{kJ} / \mathrm{mol} \cdot \mathrm{K} ; \sigma$ - stress, $\mathrm{MPa} ; \mathrm{T}$ - temperature, $\mathrm{K}$; $\tau_{\mathrm{m}}, \mathrm{U}_{0}, \gamma, \mathrm{T}_{\mathrm{m}}$ are thermal fluctuation constants.

It should be noted that the above formula is insensitive to changes in the physical structure, which lead to changes in the strength properties. There are various variants of special cases in which the formula should be modernized by introducing coefficients [10].

\section{Methods}

In this study, it is necessary to determine the transverse bending strength (breaking load), as well as to determine the time from the moment of application of a non-critical load to the destruction of the sample. To find this data a number of tests are required $[11,12]$.

To identify the temperature-time-force equivalence, it is necessary to make samples (in the form of beams) from polyvinyl chloride (Figure 1). Experiments are carried out for a solid section and two layers without the use of special ties. The length of the samples was 6 $\mathrm{cm}$. The cross section is rectangular $(\mathrm{b} \times \mathrm{h}=1.5 \mathrm{~cm} \times 0.3 \mathrm{~cm})$.

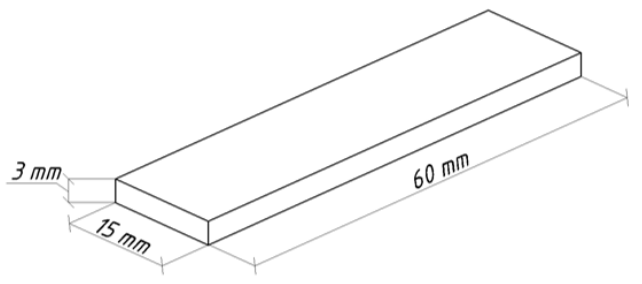

a)

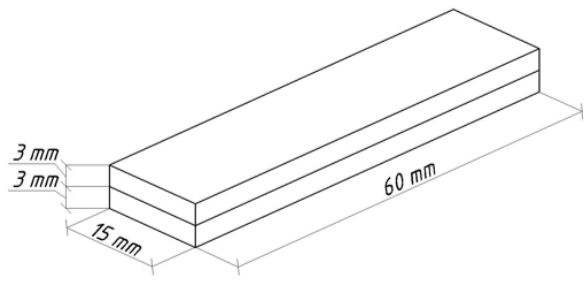

b)

Fig. 1. Test piece for testing a solid section (a) and a composite in two layers without special ties (b).

For transverse bending and fracture tests, a six-position stand was used (Figure 2). This stand consists of frame 1, which is made of channels. On the support platform of the frame 2 , two roller supports 3 are installed at a distance from each other equal to the beam span $(50 \mathrm{~mm})$. Sample 4 is placed on roller supports and loaded with a load device 5 . Sample 4 is placed on roller supports and loaded with a load device 5. Elevated temperature is created by rod electric heaters 6 . To reduce heat loss and create a directed heat flow, a casing 8 is installed and fixed to the frame on the support platform. The temperature is set by LATR $1 \mathrm{M} \mathrm{220V-9A} \mathrm{7,} \mathrm{and} \mathrm{is} \mathrm{regulated} \mathrm{by} \mathrm{the} \mathrm{EPV2-11A} \mathrm{potentiometer} \mathrm{gr.} \mathrm{XK} 0-300{ }^{\circ} \mathrm{C}$ and additionally controlled by a thermometer with an accuracy of $\pm 1^{\circ} \mathrm{C}$. It should be noted that the thermocouple and the thermometer ball are in the fracture zone of the working section of the sample $[13,14]$.

To eliminate mechanical vibrations during the destruction of samples, a damping device was used - a container filled with sand 9. 


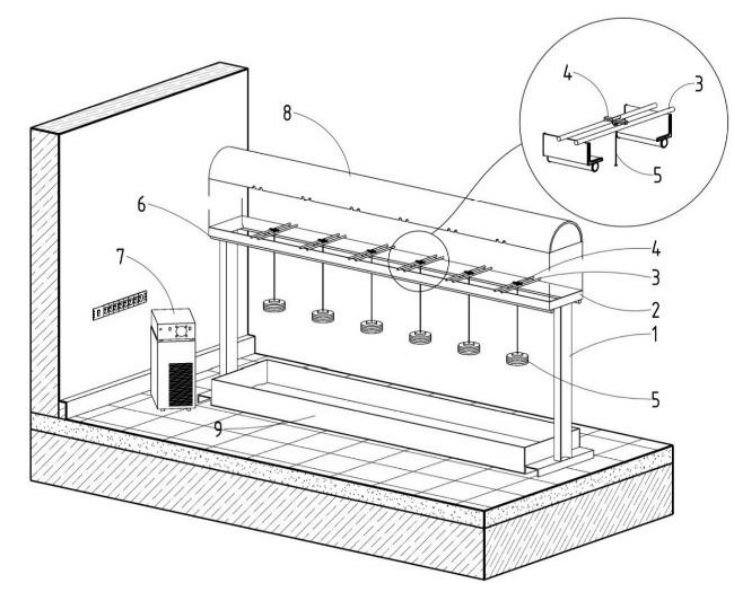

Fig. 2. Installation diagram for testing.

For short-term tests aimed at determining the strength, the sample is placed on the supports of the installation presented earlier. The distance between the supports is maintained at $5 \mathrm{~cm}$.

Then, this sample is loaded stepwise at $2.5 \mathrm{~cm}$ from the support (in the middle of the span), until failure occurs. The breaking load is found for three types of temperatures (in the case of this work, for $15,30,45^{\circ} \mathrm{C}$ ). At each temperature, the test is carried out on at least eight samples. It should be noted that the test can be carried out only after holding the samples at the required temperature for at least 2 hours, before creating the required temperature in the sample. The ultimate load is recorded and entered in the test table.

To determine the durability at each of the required temperatures, five voltages are selected with the corresponding reduction factor for the breaking stress. The choice of the optimal stress reduction factors is determined empirically and significantly affects the correctness of the experiments. Thus, the following reduction factors were selected for samples of solid section $\mu=0.950 ; 0.910 ; 0.870 ; 0.830 ; 0.790$. For samples of composite cross-section in two layers, the reduction factors $\mu=0.950 ; 0.930 ; 0.910 ; 0.890 ; 0.870$.

During full-scale experiments, the time is recorded from the moment of the beginning of loading to the onset of the critical phase of destruction. For each stage of voltage reduction, at least 8 tests are carried out under similar conditions. To increase the reliability of the results obtained, static processing is used. Then, according to the obtained experimental data, graphs are plotted in the coordinates $\lg \tau-\sigma$, which are the initial data for determining the thermal fluctuation constants.

The next step is the standard rearrangement of the family of fan-shaped lines into coordinates $\lg \tau-1000 / \mathrm{T}$. To do this, three arbitrary voltages are set, which, when rebuilding, will turn into forward voltages. The constants $\tau_{\mathrm{m}}$ and $\mathrm{T}_{\mathrm{m}}$ are determined from the pole of these straight lines.

The constants $U_{0}$ and $\gamma$ are found from the graph plotted in the coordinates $U_{0}-\sigma$. The constant $\mathrm{U}_{0}$ is the value formed along the ordinate axis $\left(\mathrm{U}_{0}, \mathrm{~kJ} / \mathrm{mol}\right)$ by the intersection point of the straight line, and $\gamma$ is the slope of the straight line taken with the opposite sign. This straight line is constructed from three points with coordinates $\left(\sigma_{i} ; U_{i}\right)[15,16]$.

\section{Results}

The statically processed values characterizing the durability of solid section specimens found during transverse bending tests are presented in Table 1. 
Table 1. Decimal logarithm values of time [sec] at specified voltages and temperatures for a solid section after statistical data processing.

\begin{tabular}{|c|c|c|c|c|c|c|c|c|c|c|c|}
\hline \multicolumn{12}{|c|}{$\begin{array}{l}\text { Average value of the logarithm of durability and the border of the confidence interval at } \\
\text { temperature }\end{array}$} \\
\hline \multirow{2}{*}{$\begin{array}{c}\sigma \\
\mathrm{MPa}\end{array}$} & \multicolumn{3}{|c|}{$15^{\circ} \mathrm{C}$} & \multirow{2}{*}{$\begin{array}{c}\sigma, \\
\mathrm{MPa}\end{array}$} & \multicolumn{3}{|c|}{$30^{\circ} \mathrm{C}$} & \multirow{2}{*}{$\begin{array}{c}\sigma \\
\mathrm{MPa}\end{array}$} & \multicolumn{3}{|c|}{$45^{\circ} \mathrm{C}$} \\
\hline & $\mathrm{L}$ & $M$ & $\mathrm{H}$ & & $\mathrm{L}$ & $M$ & $\mathrm{H}$ & & $\mathrm{L}$ & $M$ & $\mathrm{H}$ \\
\hline 13.608 & 0.029 & 0.417 & 0.805 & 13.114 & 0.009 & 0.383 & 0.757 & 12.214 & 0.130 & 0.492 & 0.854 \\
\hline 13.035 & 0.490 & 0.868 & 1.247 & 12.561 & 0.365 & 0.763 & 1.161 & 11.700 & 0.251 & 0.579 & 0.908 \\
\hline 12.462 & 1.371 & 1.712 & 2.053 & 12.009 & 1.206 & 1.494 & 1.782 & 11.185 & 0.772 & 1.131 & 1.490 \\
\hline 11.889 & 2.501 & 2.757 & 3.013 & 11.457 & 2.058 & 2.365 & 2.673 & 10.671 & 1.785 & 2.133 & 2.481 \\
\hline 11.316 & 3.208 & 3.449 & 3.689 & 10.905 & 3.071 & 3.276 & 3.481 & 10.157 & 2.258 & 2.664 & 3.070 \\
\hline
\end{tabular}

According to the statically processed data given in Table 1, a graph is built in the coordinates $\lg \tau-\sigma$ (Figure 3).

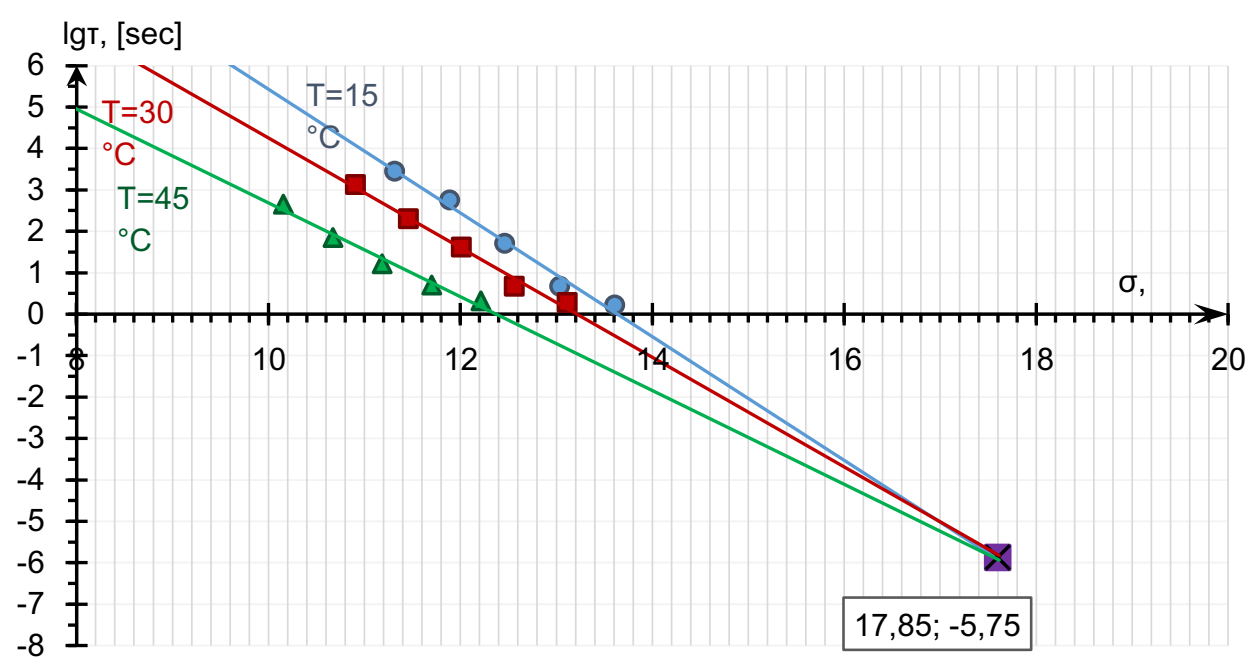

Fig. 3. "Straight beam" for solid-section specimens in the coordinates of the dependence of the logarithm of durability on stress.

For samples of solid cross-section, the straight-line dependence $\lg \tau=f(\sigma)$ at a temperature of $15{ }^{\circ} \mathrm{C}$ is described by the equation: $\lg \tau=-1.493 \cdot(\sigma)+20.365$, the correlation coefficient is $\mathrm{R}^{2}=0.986$. At a temperature of $30{ }^{\circ} \mathrm{C} \lg \tau=-1.324 \cdot(\sigma)+17.491$, at $\mathrm{R}^{2}=0.988$. At a temperature of $45^{\circ} \mathrm{C} \lg \tau=-1.132 \cdot(\sigma)+14.012$, at $\mathrm{R}^{2}=0.980$.

When rebuilding the $« \lg \tau-\sigma »$ graph into the $\langle\lg \tau-1000 / T »$ (Figure 4), stresses of 9, 10, $11 \mathrm{MPa}$ were selected. The straight-line relationship $\lg \tau=f(1000 / T)$ for a stress of $9 \mathrm{MPa}$, which is a straight-line stress of $9 \mathrm{MPa}$, is described by the equation: $\lg \tau=9.455 \cdot(1000 / T)-25.814$, with a correlation coefficient $\mathrm{R}^{2}=0.989$. Forward stress of $10 \mathrm{MPa}$ is described by the equation: $\lg \tau=8.356 \cdot(1000 / T)-23.496, \mathrm{R}^{2}=0.988$. Forward stress $11 \mathrm{MPa}$ is described by the equation: $\lg \tau=7.256 \cdot(1000 / T)-21.178$, $\mathrm{R}^{2}=0.986$. From the graph in Figure 4, you can determine the position of the pole, based on which the first two constants are determined: $\lg \tau_{m}=-5.75 \mathrm{sec}$ and $T_{m}=474 \mathrm{~K}$. 


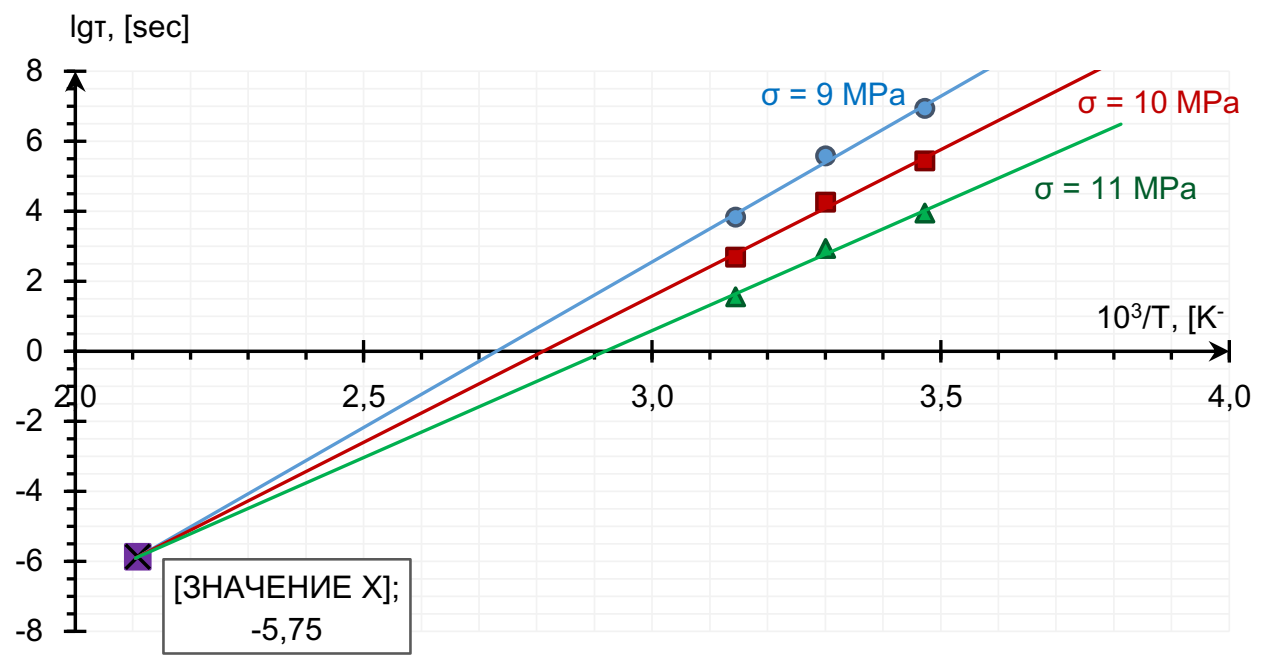

Fig. 4. "Straight beam" for solid samples in the coordinates of the dependence of the logarithm of durability on the reciprocal temperature.

The straight-line dependence for specimens of solid section $U_{0}=f(\sigma)$ (Figure 5) is described by the following equation: $U_{0}=-21.013 \cdot(\sigma)+369.831, \mathrm{R}^{2}=1$. From this equation, the last two constants are determined: $U_{0}=370 \mathrm{~kJ} / \mathrm{mol}$ and $\gamma=21 \mathrm{~kJ} /(\mathrm{MPa} \cdot \mathrm{mol})$.

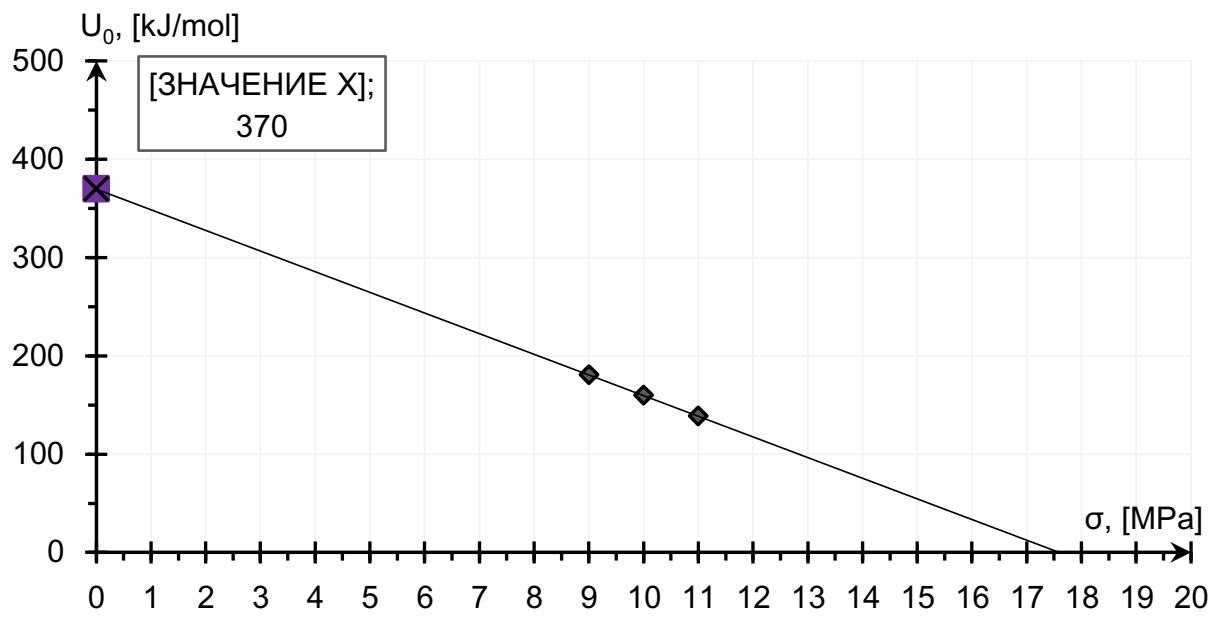

Fig. 5. Straight line for solid-section specimens in the coordinates of the dependence of the activation energy on the stress.

The statically processed values characterizing the durability of samples of a composite section in two layers without special bonds, found during transverse bending tests, are presented in Table 2 . 
Table 2. Values of the decimal logarithm of time [sec] at given stresses and temperatures for a composite section in two layers after statistical data processing.

\begin{tabular}{|c|c|c|c|c|c|c|c|c|c|c|c|}
\hline \multicolumn{12}{|c|}{$\begin{array}{c}\text { Average value of the logarithm of durability and the border of the confidence interval at } \\
\text { temperature }\end{array}$} \\
\hline \multirow{2}{*}{$\begin{array}{c}\sigma \\
\mathrm{MPa}\end{array}$} & \multicolumn{3}{|c|}{$15^{\circ} \mathrm{C}$} & \multirow{2}{*}{$\begin{array}{c}\sigma \\
\mathrm{MPa}\end{array}$} & \multicolumn{3}{|c|}{$30^{\circ} \mathrm{C}$} & \multirow{2}{*}{$\begin{array}{c}\sigma, \\
\mathrm{MPa}\end{array}$} & \multicolumn{3}{|c|}{$45^{\circ} \mathrm{C}$} \\
\hline & $\mathrm{L}$ & $\mathrm{M}$ & $\mathrm{H}$ & & $\mathrm{L}$ & $\mathrm{M}$ & $\mathrm{H}$ & & $\mathrm{L}$ & $\mathrm{M}$ & $\mathrm{H}$ \\
\hline 15.560 & 0.251 & 0.579 & \begin{tabular}{|l|}
0.908 \\
\end{tabular} & 15.160 & \begin{tabular}{|l|}
0.117 \\
\end{tabular} & & \begin{tabular}{|l|}
0.692 \\
\end{tabular} & 14.580 & -0.088 & 0.270 & 0.628 \\
\hline 15.232 & 0.380 & 0.872 & 1.364 & 14.841 & \begin{tabular}{|l|}
0.172 \\
\end{tabular} & 0.589 & \begin{tabular}{|l|}
1.007 \\
\end{tabular} & 14.273 & 0.147 & 0.559 & 0.970 \\
\hline 14.905 & 1.350 & 1.671 & 1.992 & 14.522 & \begin{tabular}{|l|}
0.645 \\
\end{tabular} & 1.157 & \begin{tabular}{|l|}
1.669 \\
\end{tabular} & 13.967 & 0.568 & 0.953 & 1.337 \\
\hline 14.577 & 2.673 & 3.098 & 3.523 & 14.203 & \begin{tabular}{|l|}
1.553 \\
\end{tabular} & 2.035 & 2.516 & 13.660 & 1.404 & 1.794 & 2.184 \\
\hline 14.249 & 3.395 & 3.682 & 3.969 & 13.884 & \begin{tabular}{|l|}
2.817 \\
\end{tabular} & 3.201 & 3.586 & 13.353 & 2.471 & 2.790 & 3.108 \\
\hline
\end{tabular}

According to the statically processed data given in Table 2, a graph is built in the coordinates $\lg \tau-\sigma$ (Figure 6).

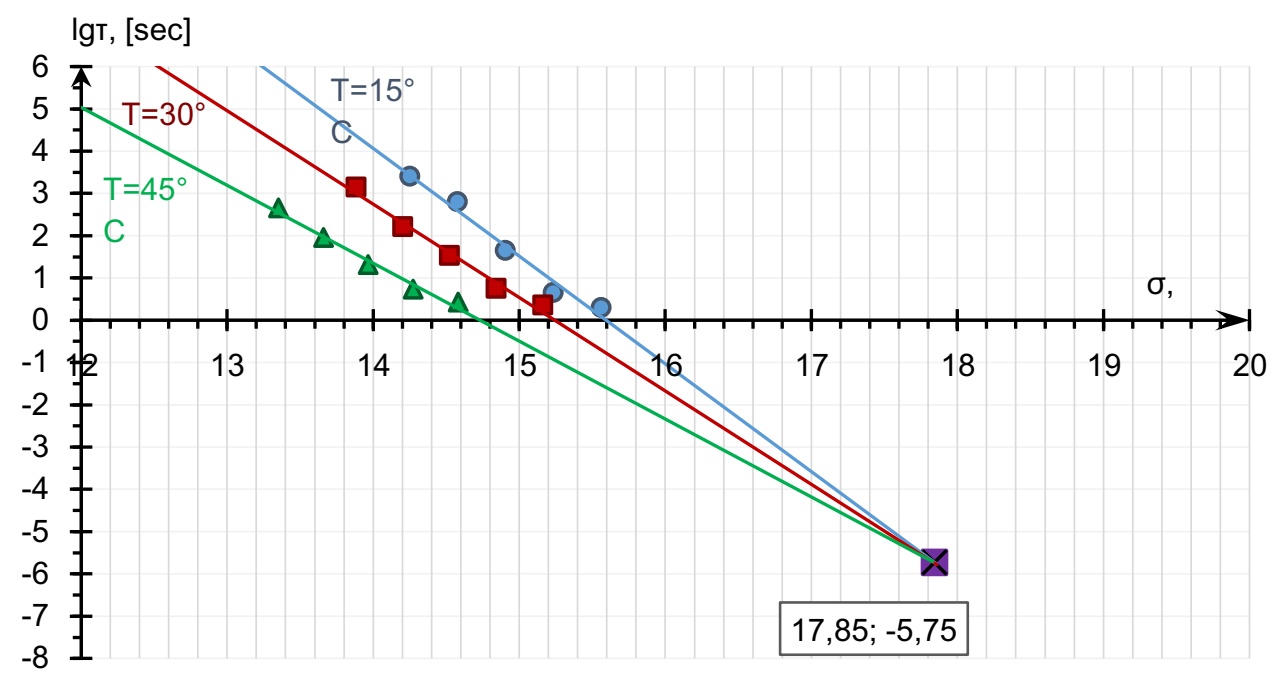

Fig. 6. "Straight beam" for samples of compound cross-section in two layers in the coordinates of the dependence of the logarithm of durability on stress.

For samples of composite cross-section in two layers, the linear dependence $\lg \tau=f(\sigma)$ at a temperature of $15{ }^{\circ} \mathrm{C}$ is described by the equation: $\lg \tau=-2.549 \cdot(\sigma)+39.747$, the correlation coefficient is $\mathrm{R}^{2}=0.975$. At a temperature of 30 ${ }^{\circ} \mathrm{C} \quad \lg \tau=-2.209 \cdot(\sigma)+33.668$, at $\mathrm{R}^{2}=0.984$. At a temperature of $45{ }^{\circ} \mathrm{C}$ $\lg \tau=-1.843 \cdot(\sigma)+27.154$, at $\mathrm{R}^{2}=0.982$.

When rebuilding the « $\lg \tau-\sigma »$ graph into the $« \lg \tau-1000 / T »$ graph (Figure 7), stresses of 12, 13, $14 \mathrm{MPa}$ were selected. The straight-line relationship $\lg \tau=f(1000 / T)$ for a stress of $12 \mathrm{MPa}$, which is a forward stress of $12 \mathrm{MPa}$, is described by the equation: $\lg \tau=12.571 \cdot(1000 / T)-34.431$, with a correlation coefficient $\mathrm{R}^{2}=0.997$. The forward stress of $13 \mathrm{MPa}$ is described by the equation: $\lg \tau=10.419 \cdot(1000 / T)-29.519$, $\mathrm{R}^{2}=0.997$. Forward stress of $14 \mathrm{MPa}$ is described by the equation: $\lg \tau=8.268 \cdot(1000 / T)-24.607, \mathrm{R}^{2}=0.997$. From the graph in Figure 7 , you can 
determine the position of the pole, from which the first two constants are determined: $\lg \tau_{m}=-5,75$ sec и $T_{m}=438 \mathrm{~K}$.

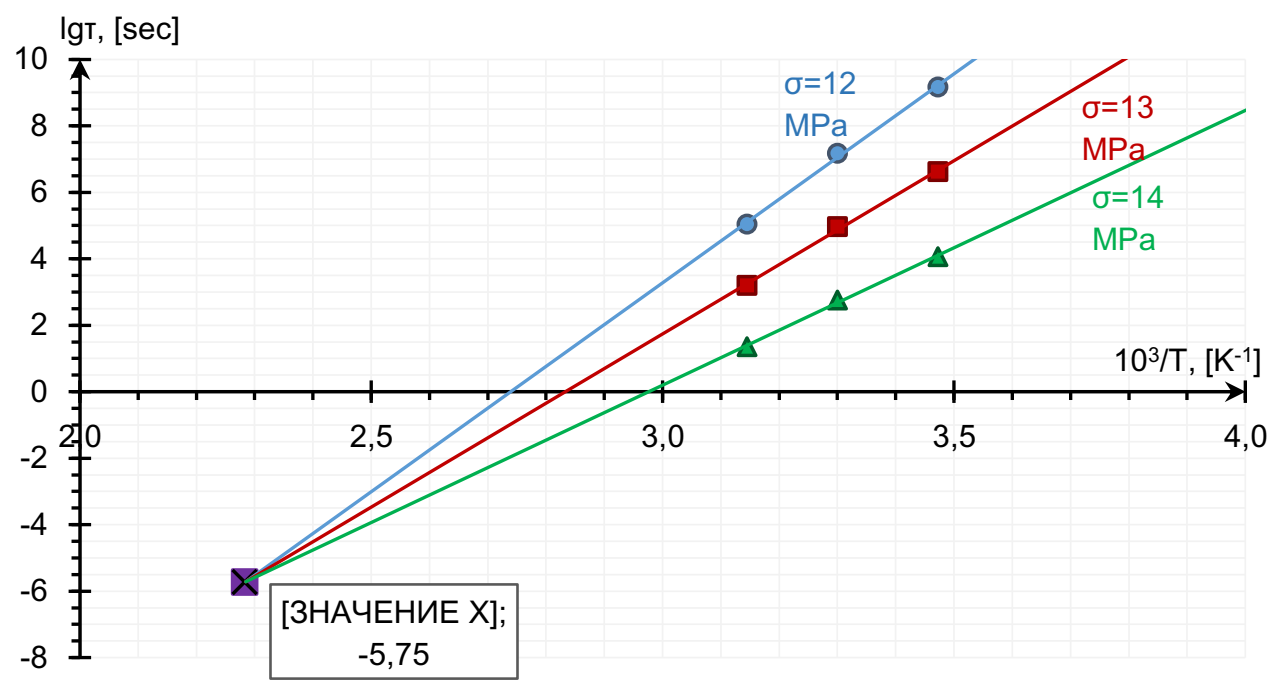

Fig. 7. "Straight beam" for samples of composite cross-section in two layers in the coordinates of the dependence of the logarithm of the durability on the reciprocal temperature.

The straight-line dependence for specimens of solid section $U_{0}=f(\sigma)$ (Figure 8) is described by the following equation: $U_{0}=-41.122 \cdot(\sigma)+733.733, \mathrm{R}^{2}=1$. From this equation, the last two constants are determined: $U_{0}=734 \mathrm{~kJ} / \mathrm{mol}$ and $\gamma=41$ $\mathrm{kJ} /(\mathrm{MPa} \cdot \mathrm{mol})$.

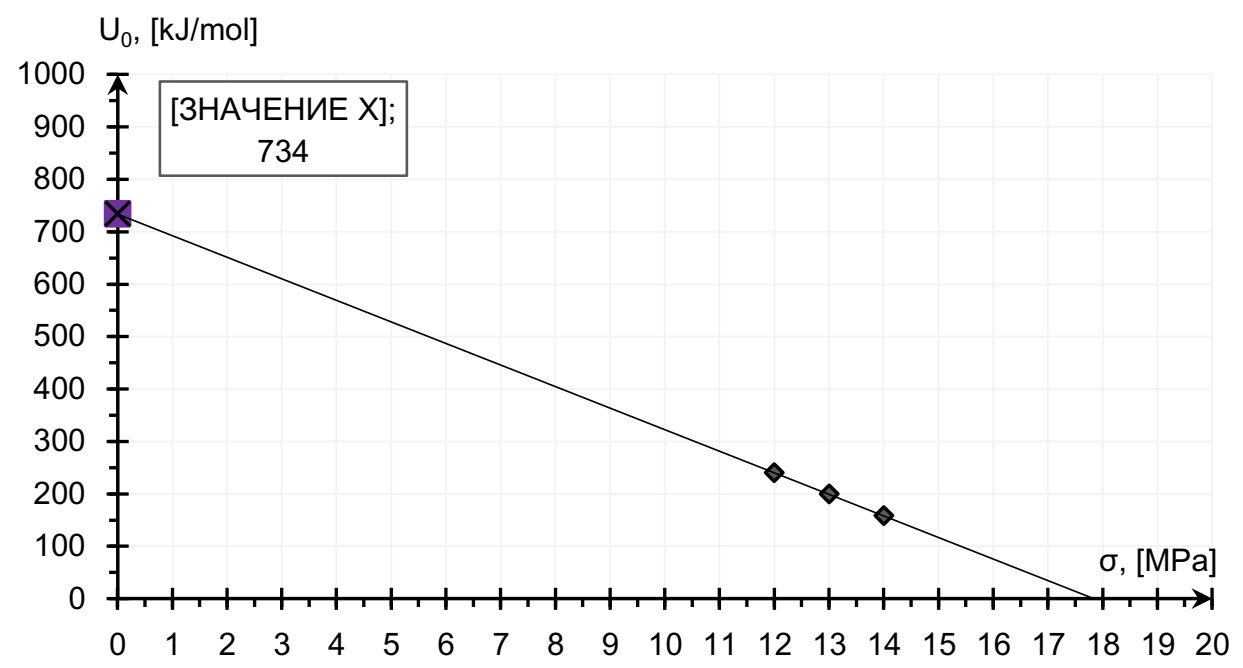

Fig. 8. Straight line for samples of composite cross-section in two layers in the coordinates of the dependence of the activation energy on the stress. 


\section{Discussion}

The found thermal fluctuation constants for a solid section and a section in two layers without special bonds are summarized in Table 3. It should be noted that in all cases the constant $\lg \tau_{m}$ is constant. Also, the constant $T_{m}$ has minor deviations, which are the error of the graphic-analytical method. Based on this, we can say that these constants are insensitive to changes in the section configuration.

Also, in a comparative analysis, it was noticed that the constants $U_{0}$ and $\gamma$ differ, adjusted for the error, by exactly 2 times.

Table 3. Thermal fluctuation constants for a solid section and a section in two layers without special constraints.

\begin{tabular}{|c|c|c|c|c|}
\hline \multirow{2}{*}{ Section view } & \multicolumn{4}{|c|}{ Empirical constants } \\
\cline { 2 - 5 } & $\lg \tau_{m}, \mathrm{sec}$ & $T_{m}, \mathrm{~K}$ & $\begin{array}{c}U_{0}, \\
\mathrm{~kJ} / \mathrm{mol}\end{array}$ & $\begin{array}{c}\gamma, \\
\mathrm{kJ} /(\mathrm{MPa} \cdot \mathrm{mol})\end{array}$ \\
\hline Solid section & -5.75 & 474 & 370 & 21 \\
\hline $\begin{array}{c}\text { Two layers without special } \\
\text { constraints }\end{array}$ & -5.75 & 438 & 734 & 41 \\
\hline
\end{tabular}

It should be noted that a similar result was obtained for wood samples [17,18]. Since wood is an anisotropic material, and polyvinyl chloride is isotropic, it can be said with confidence that this material property does not affect the revealed pattern.

As a result, based on the found patterns and features of the mathematical expression of the thermal fluctuation concept, we can talk about the following form of the Zhurkov's equation for composite sections without special constraints:

$$
\tau=\tau_{m} \cdot \exp \left[k_{c} \cdot\left(\frac{U_{0}-\gamma \cdot \sigma}{R} \cdot\left(\mathrm{T}^{-1}-\mathrm{T}_{m}^{-1}\right)\right)\right]
$$

The factor in this equation for a composite section of two layers without special bonds is $k_{c}=2$. It was also found that the anisotropy or isotropy of the material does not affect these regularities.

\section{Conclusions}

Based on the study carried out, the laws of deformation and destruction of polymer (polyvinyl chloride) elements of solid sections and a composite section without a special joint in two layers have been theoretically substantiated and experimentally revealed. Thus, considering the configuration of the section of the elements of a composite section without special connections in two layers is proposed by introducing the coefficient $k_{c}$ into the generalized Zhurkov's equation. For the investigated PVC sheet elements of composite cross-section in two layers, the coefficient is $k_{c}=2$. Based on the data of previous researchers, it was found that for any elements of composite sections in two layers without special bonds, the ability of the material to isotropy or anisotropy does not affect its performance from the thermal fluctuation position. 


\section{References}

1. V.R. Regel, A.I. Slutsker, E.E. Tomashevsky, The Kinetic Nature of the Strength of Solids (1974)

2. S. Sokolova, N. Smirnova, MATEC Web of Conferences (2018)

3. E. I. Pakhomov, National priorities of Russia 1, 3 (2015)

4. V.M. Mishin, D.V. Shchitov, M.V. Volokonsky, Bulletin of the Tambov State Technical University 23, 236 (2018)

5. A.A. Tager, Physicochemistry of polymers (1968)

6. V.P. Yartsev, Physical and technical foundations of the performance of organic materials in parts and structures (1998)

7. L.B. Potapova, V.P. Yartsev, How Are Ultimate Stresses Predicted? (2005)

8. V.G. Mikulsky, Construction Materials (1996)

9. V.N. Bogoslovsky, V.M. Rightman, N.A. Parfentieva, Proceedings of universities. Building 9 (1982)

10. S.B. Ratner, V.P. Yartsev, Thermal fluctuation patterns of polymer abrasion (1978)

11. V.I. Loganina, T.V. Uchaeva, P.V. Monastyrev, Journal of Engineering and Applied Sciences 11 (2016)

12. S.A. Mamontov, V.P. Yartsev, P.V. Monastyrev, Textile industry technology 1 (2017)

13. S.N. Zhurkov, S.A. Abasov, Polymer Science 41, 12 (1999)

14. S.N. Zhurkov, Solid State Physics 22, 11 (1988)

15. V.P. Yarcev, O.A. Kiseleva, Advanced Materials and Technologies 4, 16 (2019)

16. V.P. Yarcev, Bulletin of the Tambov State Technical University 12, 1 (2006)

17. A.V. Erofeev, S.P. Skvortsov, P.A. Mukhortov, Vestnik KRSU 17, 12 (2017)

18. P.A. Mukhortov, Architecture and construction 3, 9 (2019) 